\title{
SISTEMAS AGROALIMENTARES E REDES DE COMERCIALIZAÇÃO: UMA OUTRA RELAÇÃO AMBIENTE-SOCIEDADE
}

\author{
Bruna Schmidt Gemim* \\ Thamy Numer** \\ Valdir Frigo Denardin*** \\ Valter Roberto Schaffrath ${ }^{* * * *}$
}

\begin{abstract}
Resumo
As questões ambientais permeiam todos os setores da sociedade contemporânea, seja na esfera econômica, política ou social. A crise ambiental se apresenta como a manifestação dos padrões civilizatórios hegemônicos de se relacionar com o ambiente, ideologicamente voltados ao progresso e ao crescimento. Para o enfrentamento de tais problemáticas é preciso repensar a relação sociedade-natureza a partir de uma profunda transformação da perspectiva do homem diante do ambiente e como parte deste. Além disso, não se pode admitir que apenas um modo de vida, produção e reprodução prevaleça sobre os demais. Nesse sentido, o presente trabalho procura identificar como as questões socioambientais e de desenvolvimento permeiam os sistemas agroalimentares, assim como formas de resistência e ressignificação das relações sociais voltadas à comercialização de alimentos, apresentando a experiência do Projeto Redes de Comercialização da Cooperativa Motirõ, no Litoral do Paraná, como promotora de outra lógica de comercialização de alimentos. Trilhando novos caminhos na busca pela sustentabilidade da produção de alimentos e da reprodução social dos camponeses, com vista à soberania e segurança alimentar, ressignificando as relações sociais campo-cidade, ou seja, onde se dá a produção do alimento e encontram-se seus consumidores.
\end{abstract}

Palavras-chave: Sociedade-natureza. Desenvolvimento local. Circuitos curtos de comercialização.

\footnotetext{
* Bióloga, Especialista em Ciência e Tecnologia do Ambiente, Mestranda no Programa de Pós-Graduação em Meio Ambiente e Desenvolvimento da Universidade Federal do Paraná - PPGMADE/UFPR.

** Mestranda no Programa de Pós-Graduação em Meio Ambiente e Desenvolvimento da Universidade Federal do Paraná PPGMADE/UFPR.

*** Doutor em Ciências Sociais em Desenvolvimento, Agricultura e Sociedade, Professor da Universidade Federal do Paraná - Setor Litoral e do Programa de Pós-Graduação em Meio Ambiente e Desenvolvimento - PPGMADE/UFPR.

**** Doutor em Agronomia, Professor do Instituto Federal do Paraná - Campus Curitiba e do Programa de Pós-Graduação em Meio Ambiente e Desenvolvimento - PPGMADE/UFPR.
} 


\section{Introdução}

A utilização de recursos naturais e a geração de resíduos é algo natural, inevitável e comum a qualquer espécie. A preocupação com o meio ambiente surge quando esses recursos são utilizados a um ritmo maior do que as capacidades da natureza em reproduzi-los ou quando os resíduos gerados superam a capacidade de absorção, ou seja, os problemas ambientais revelam uma contradição entre o ritmo dos ciclos biogeoquímicos e o ritmo dos ciclos de produção humana (TOMMASINO et al., 2005).

As questões ambientais permeiam todos os setores da sociedade contemporânea, seja na esfera econômica, política ou social. Diante da crise ambiental global, um corpo de preceitos tem acompanhado as estratégias e políticas de desenvolvimento sustentável, que remetem ao primeiro "Dia da Terra” em 1970 e às Conferências das Nações Unidas sobre Meio Ambiente Humano (ESTOCOLMO, 1972), Meio Ambiente e Desenvolvimento (Rio 92), Rio +10 , dentre outros, assim como a publicação de obras clássicas do ambientalismo, como "A Primavera Silenciosa", "A Bomba Populacional", "Os Limites do Crescimento", "Nosso Futuro Comum”, os "Princípios do Rio" e a "Carta da Terra" (PNUMA, 2002).

A Revolução Industrial e a posterior industrialização da agricultura, conhecida como Revolução Verde, baseada em sementes melhoradas, mecanização, monocultivos e uso intensivo de fertilizantes e agrotóxicos, caracterizam-se como protagonistas no cenário da crise ambiental. Esse modelo hegemônico de agricultura, altamente mecanizado e dependente de insumos externos à propriedade, tem sido gerador de modificações no uso e na relação com a terra, assim como nas relações sociais no campo, promovendo impactos socioambientais antes desconhecidos.

Aos impactos ambientais gerados pela agricultura hegemônica soma-se à intensa circulação de alimentos que, devido à liberalização dos mercados e importações/exportações, acarretam grandes deslocamentos, em detrimento de uma produção voltada para o autoconsumo local (PEREZCASSARINO, 2013). Complementa isso Sachs (2010, p. 25), para quem "[...] o desenvolvimento rural oficialmente includente e em harmonia com o meio ambiente exige soluções intensivas em conhecimentos e mão de obra, econômicas em capital e recursos naturais".

Dessa forma, verifica-se uma nova lógica de organização territorial do desenvolvimento, a partir da coexistência de “[...] experiências originais de auto-organização socioeconômica, sociocultural e sociopolítica no nível local." (VIEIRA, 2009, p. 44), que recriam identidades territoriais, em contrapartida ao desmantelamento do setor público, à redução de investimentos sociais nos países do Sul e às coações geradas pela globalização neoliberal (VIEIRA, 2009). 
A partir dessa racionalidade, busca-se a construção de sistemas agroalimentares alternativos em escala local, voltados ao desenvolvimento rural e à reconexão desses processos com a sua base ecológica e sociocultural. Que, segundo Perez-Cassarino e Ferreira (2013, p. 174), “[...] visem e realizem articulações regionais, nacionais e internacionais, tendo como um dos pilares de sustentação a construção de circuitos curtos de proximidade de comercialização e a valorização dos mercados locais".

Importante ressaltar que por muito tempo, estudiosos dos processos de mercantilização, entendiam que a relação entre os mercados e camponeses era prejudicial a estes. Somente a partir dos anos 1990, Ploeg demonstrou que a mercantilização não é, necessariamente, um processo de ruptura total das bases de produção de pequenos agricultores e que a inserção destes nos mercados poderia fortalecer a base interna, ampliando sua autonomia (SCHNEIDER, 2016). Entre as experiências, práticas e políticas que contribuem para valorizar os produtos locais e contribuem para a relocalização das atividades produtivas, os circuitos curtos de comercialização têm papel relevante. Circuitos curtos caracterizam-se pela proximidade geográfica entre produtores e consumidores, pela participação ativa do consumidor e, até no máximo, um intermediário entre ambos (DAROLT, 2013), como forma de impulsionar o desenvolvimento local, a soberania e segurança alimentar, a autonomia e a reprodução social no campo.

Nesse sentido, o presente trabalho apresenta um ensaio teórico que procura identificar como as questões socioambientais e de desenvolvimento permeiam os sistemas agroalimentares, assim como formas de resistência e ressignificação das relações sociais voltadas à comercialização de alimentos, apresentando a experiência do Projeto Redes de Comercialização da Cooperativa Motirõ, no Litoral do Paraná, como promotora de uma lógica de comercialização de alimentos diferenciada.

\section{Desenvolvimento e Meio Ambiente nas Sociedades Contemporâneas, com foco na América Latina}

$\mathrm{Na}$ história contemporânea, o conceito de desenvolvimento tem sido utilizado em distintos sentidos, referindo-se: à evolução de um sistema social de produção, com acumulação e progresso de técnicas, elevando a produtividade do conjunto da sua força de trabalho; ou ao grau de satisfação das necessidades humanas elementares, tais como alimentação, vestimentas, habitação e aumento na expectativa de vida da população, além disso, no sentido de apropriação de grupos dominantes na utilização de recursos escassos, demonstrando que a concepção de desenvolvimento de uma sociedade não é alheia à sua estrutura social (FURTADO, 1980).

Nessa direção, Veiga (2006,p.166) afirma que “[...] o desenvolvimento tem sido exceção histórica e não regra geral.”, pois para haver 
desenvolvimento, o crescimento econômico deve se refletir em ampliação das capacidades humanas. Já para Furtado (1974), o desenvolvimento não passa de um mito, ao propagar que o desenvolvimento econômico praticado pelos países desenvolvidos pode ser universalizado. Esse pensamento foi, e tem sido, utilizado para

[...] mobilizar os povos da periferia e levá-los a aceitar enormes sacrifícios, para legitimar a destruição de formas de cultura arcaicas, para explicar e fazer compreender a necessidade de destruir o meio físico e para justificar formas de dependência que reforçam o caráter predatório do sistema produtivo. (FURTADO, 1974, p. 75).

A Revolução Industrial possibilitou a generalização das relações capitalistas, produzindo significativas modificações na relação do ser humano com a natureza, mas foi logo depois da Segunda Guerra Mundial, no início dos anos 1950, que a ideia de desenvolvimento como crescimento econômico ganhou força, a partir de uma conjuntura histórica que manifesta sua vontade de reestruturar todas as sociedades subdesenvolvidas, com vistas à prosperidade material e progresso econômico (TOMMASINO et al., 2005; ESCOBAR, 2007; GUDYNAS, 2011). Em poucos anos, essa racionalidade econômica de desenvolvimento já era hegemônica, sendo as Nações Unidas a responsável por um dos documentos mais influentes da época, que tinha por objetivo desenhar políticas e medidas concretas para o desenvolvimento econômico dos países subdesenvolvidos, afirmando que:

[...] o progresso econômico acelerado é impossível sem ajustes dolorosos. As filosofias ancestrais devem ser erradicadas; as velhas instituições sociais têm que desintegrar-se; os laços de casta, credo e raça devem romper-se; e grandes massas de pessoas incapazes de seguir o ritmo do progresso deverão ver frustradas suas expectativas de vida cômoda. Muitas poucas comunidades estão dispostas a pagar o preço do progresso econômico. (United Nations, 1951 apud ESCOBAR, 2007, p. 20).

Diante dessa manifestação das Nações Unidas, inúmeros foram os estudos e críticas às concepções de desenvolvimento nela apresentada, até que na década seguinte, a mesma organização se redime do seu posicionamento lançando a "Década do Desenvolvimento das Nações Unidas: Propostas para a Ação”, em 1962, na qual insistem na separação do desenvolvimento e crescimento, de aspectos qualitativos e quantitativos, abarcando as questões sociais e culturais, e não somente econômicas (GUDYNAS, 2011).

As diferenças entre o conceito de crescimento econômico e desenvolvimento, assim como de que forma o crescimento poderia se traduzir em desenvolvimento, são elucidados de maneira muito clara por Celso Furtado no seguinte trecho: 
[...] o crescimento econômico, tal qual o conhecemos, vem se fundando na preservação dos privilégios das elites que satisfazem seu afã de modernização; já o desenvolvimento se caracteriza pelo seu projeto social subjacente. Dispor de recursos para investir está longe de ser condição suficiente para preparar um melhor futuro para a massa da população. Mas quando o projeto social prioriza a efetiva melhoria das condições de vida dessa população, o crescimento se metamorfoseia em desenvolvimento. (FURTADO, 2004, p. 484).

Segundo Zannoni e Raynaut (2015, p. 13), “[...] não se pode conceber um desenvolvimento das sociedades humanas em detrimento do sistema Natureza; da mesma forma, não se pretende proteger os meios naturais às custas de intoleráveis disfunções no sistema Sociedade”. Nesse sentido, em 1972, em Estocolmo, teve início a discussão sobre os padrões de desenvolvimento, com a formulação posterior do relatório Brundtland, denominado "Nosso Futuro Comum", na Comissão Mundial sobre Meio Ambiente e Desenvolvimento da Organização das Nações Unidas (ONU), em 1987; e enfim, a popularização do termo "desenvolvimento sustentável", como conceito que alia produção e desenvolvimento com o cuidado ao meio ambiente (HACON; FIGUEIREDO, 2014).

Seguindo esse raciocínio, as políticas ambientais e de desenvolvimento sustentável têm sido baseadas em um conjunto de princípios e em uma consciência ecológica que tem servido como critério para orientar as ações dos governos, das instituições internacionais e a cidadania (PNUMA, 2002).Porém, no debate sobre conflitos e questões ambientais, assim como na elaboração e aplicação de modelos de desenvolvimento, ignoram-se as diferenças socioculturais e as desigualdades econômicas dentre os diversos grupos sociais, atribuindo uma aparente coletividade na socialização dos problemas e na distribuição dos benefícios (HACON; FIGUEIREDO, 2014).

No contexto latino-americano, o surgimento e a construção da abordagem socioambiental se dão a partir da reflexão e o debate sobre a sociedade civil, a questão ambiental, a sustentabilidade e o desenvolvimento, somados a duas importantes características da América Latina: a rica biodiversidade e a exclusão social (ALBUQUERQUE, 2011). Desse modo, a natureza representa um fator decisivo na "construção da América Latina Ocidental”, tanto para o imaginário do Ocidente quanto para a identidade dos próprios latino-americanos em relação aos seus antigos colonizadores (FERREIRA et al., 2011).

Historicamente, a América Latina caracteriza-se por sociedades de estruturas oligárquicas e paternalistas, baseadas por relações de poder e controle do Estado, nas quais as questões ambientais ultrapassam os limites da gestão dos recursos naturais para adentrar o campo das disputas sociais por sentidos culturais (ALBUQUERQUE, 2011; HACON; FIGUEIREDO, 2014). Segundo Veiga (2006), os benefícios do crescimento têm servido para 
reforçar essa matriz institucional, ao invés de transformá-la para melhoria do acesso das populações mais vulneráveis aos seus direitos fundamentais.

O Brasil segue nessa mesma direção, apresentando alarmantes desigualdades de gênero, raça, região e riqueza, além de péssimas condições de pobreza, saúde e educação, devido ao estilo, ou à qualidade, de seu crescimento no período de 1930-1960, seguido do "milagre" econômico, 1967-1973, atribuído ao período da ditadura militar (VEIGA, 2006). Aos problemas socioeconômicos somaram-se os problemas ambientais, em grande medida advindos do acelerado processo de industrialização e de urbanização dos anos 1940, mas foi no período da ditadura militar (1964-1985), que a consciência da perspectiva ambiental ganhou força (ZANONI; RAYNAUT, 2015). Desde então, o País vem confirmando presença importante no cenário de negociações e acordos na agenda ambiental internacional, apesar das contradições acerca do seu efetivo comprometimento no desenvolvimento sustentável no âmbito local (GUIMARÃES; BEZERRA, 2011). Porém o cenário aponta para uma possível reversão nessa tendência de protagonismo do Brasil com o atual governo.

Para o enfrentamento das problemáticas ambientais é preciso repensar a relação sociedade-natureza a partir de uma profunda transformação na perspectiva do homem diante do ambiente e como parte deste. Nessa perspectiva, para Zaoual (2003), as crises internas do modelo hegemônico vigente apontam para a necessidade de uma civilização baseada na diversidade, na qual todas as concepções de mundo desempenham seu papel para o futuro do mundo, e no qual nenhum modelo poderá ser hegemônico sobre as outras formas de vida econômica e social, visto que o "[...] nosso mundo contém, em realidade, vários mundos.” (ZAOUAL, 2003, p. 61).

Pode-se afirmar que a crise ambiental se apresenta como a manifestação dos padrões civilizatórios hegemônicos de se relacionar com o ambiente, ideologicamente voltados ao progresso e ao crescimento. A partir dessa racionalidade, tem-se uma ordem social que se apropria do ambiente sinalizando o distanciamento entre o social e o ambiental. Para pensar uma sociedade de base ecológica, voltada ao desenvolvimento sustentável, na qual se vincula o homem e o ambiente biofísico, é preciso partir de um pensamento decolonial, com vistas ao bem viver, indigenização (plural), coabitação, plurinacionalidade e interculturalidade, que represente a construção de novas formas de um universo de duas cores para um multicolorido, que reivindica um jeito próprio de viver.

\section{A Questão do Desenvolvimento e Meio Ambiente nos Sistemas Agroalimentares e Redes de Comercialização}

Nas palavras de Zannoni e Raynaut (2015, p. 23), “[...] a resolução dos problemas de meio ambiente e de desenvolvimento passa pela busca 
de soluções endógenas, isto é, que emanem da vontade livre da sociedade e que se apoiem na realidade socioeconômica, cultural e natural regional". Nesse sentido, para Max-Neef (2012, p. 22), o desenvolvimento deve ser orientado para a satisfação das necessidades humanas fundamentais, a autodependência e as articulações orgânicas do homem com a natureza, no qual existem condições para que as pessoas sejam "protagonistas do seu próprio futuro".

Para isso, não se pode admitir que apenas um modo de vida, produção e reprodução prevaleça sobre os demais. A partir dessa premissa, o Manifesto pela Vida, do Programa das Nações Unidas para o Meio Ambiente (PNUMA, 2002), afirma que:

[...] a crise ambiental é uma crise de civilização. É a crise de um modelo econômico, tecnológico e cultural que tem depredado a natureza e negado as culturas alternativas. O modelo civilizatório dominante degrada o ambiente, subvaloriza a diversidade cultural e desconhece ao Outro (ao indígena, ao pobre, à mulher, ao negro, ao Sul) enquanto privilegia um modo de produção e um estilo de vida insustentáveis que se tornaram hegemônicos no processo de globalização. É o resultado de uma visão mercantilista do mundo que, ignorando os limites biofísicos da natureza e os estilos de vida das diferentes culturas, está acelerando o aquecimento global do planeta. A crise ambiental é uma crise moral de instituições políticas, de aparatos jurídicos de dominação, de relações sociais injustas e de uma racionalidade instrumental em conflito com a trama da vida. (PNUMA, 2002).

Nessa lógica, a globalização econômico-financeira e cultural, que impõe uma série de incertezas, coações e oportunidades, exige uma reorganização socioeconômica, sociocultural e político-institucional, como a emergência de novas formas de reciprocidade econômica, que emergem:

[...] pela formação de um tecido social especialmente coesivo e cooperativo: a estruturação de sistemas produtivos locais em zonas rurais, integrados em redes de pequenas e médias empresas que transcendem a esfera das relações puramente mercantis e desvelam novos tipos de atividade não-agrícola no meio rural; e a pesquisa de novos arranjos institucionais descentralizados e voltados para o exercício da governança local e territorial, da equidade, da busca de sinergia entre as comunidades locais e os diferentes âmbitos de regulação estatal, e da gestão patrimonial dos recursos e dos meios naturais. (VIEIRA, 2009, p. 44).

Nesse contexto, segundo Perez-Cassarino (2013, p. 140), “[...] a questão alimentar tem relação direta com os processos de desenvolvimento de uma nação”. Para o autor, a questão alimentar constitui função básica para a manutenção da vida, mas também revela uma estrutura de produção, 
beneficiamento e distribuição permeada por interesses corporativos e apropriação de capital, que, ao mesmo tempo em que possibilita uma produção em massa de alimentos, impossibilita a milhões o seu acesso.

Para Ploeg (2008), é possível destacar dois modelos de produção e consumo, um centrado na construção e reprodução de circuitos curtos e descentralizados que aliam produção e consumo de alimentos, a agricultura e a sociedade regional; e outro, centralizado e formado por grandes empresas de processamento e comercialização de alimentos, denominado pelo autor como Impérios, no qual a produção e consumo estão desconectados entre si, tanto no tempo como no espaço.

Segundo Gliessman (2000, p. 600), “[...] à medida que reconhecemos a influência de fatores sociais, econômicos, culturais e políticos sobre a agricultura, devemos também mudar nosso enfoque, da sustentabilidade dos agroecossistemas para a sustentabilidade de nossos sistemas alimentares". Para o autor, os sistemas alimentares têm amplitude global, compreendendo todos os aspectos da produção, distribuição e consumo de alimentos, que incluem:

a) relações econômicas entre proprietários de terras e assalariados agrícolas, produtores e consumidores de alimentos, cidadãos de países desenvolvidos e de países em desenvolvimento;

b) os sistemas políticos que controlam esses relacionamentos;

c) as estruturas sociais que influenciam o relacionamento das pessoas com a produção e o consumo de alimentos;

d) os sistemas culturais que influenciam os valores e crenças das pessoas. Para que os sistemas alimentares sejam sustentáveis, todos os seus aspectos humanos devem dar suporte à sustentabilidade de seus aspectos ecológicos. (GLIESSMAN, 2000, p. 600).

Também Friedmann (2000) afirma que, para atingir uma reconstrução dos sistemas agroalimentares locais, é preciso um suporte governamental, por meio de políticas públicas que incentivem a circulação e acesso aos alimentos, a prática de outras formas de agricultura e comercialização, com vistas ao desenvolvimento sustentável territorial. Porém, para o autor, somente "[...] se o Norte reduzir a demanda através da concentração nas suas próprias economias alimentícias regionais, o Sul terá a opção de (re) construir suas economias alimentícias regionais também. [...] como corretivo para os efeitos desestabilizadores e empobrecedores dos atuais padrões de demanda." (FRIEDMANN, 2000, p. 12).

Em relação a outras formas de se comercializar alimentos, os circuitos curtos nos trazem uma rica diversidade de produtos, principalmente no ramo da produção ecológica. Segundo Perez-Cassarino e Ferreira (2013), os princípios da Agroecologia têm papel fundamental na construção de mercados e na constituição de sistemas agroalimentares alternativos. 
Para os autores, "[...] a agroecologia fornece os elementos concretos que possibilitam o redesenho dos sistemas agroalimentares, no sentido de sua descentralização e adequação ambiental, social, cultural e econômica”.

Gonçalves e Mascarenhas (2018) reforçam a necessidade de aproximação entre consumidores e produtores como prática de resistência a partir da ação coletiva. Mostram a existência concreta de grupos de consumo responsável (GCRs), que são iniciativas de pessoas que questionam a lógica de abastecimento alimentar tradicional e se organizam coletivamente para exercer o ato de compra de forma criteriosa. Segundo os autores, essas iniciativas possibilitam, além das compras coletivas, a observação de como se dá a produção: de base ecológica, da agricultura familiar, de economia solidária, da reforma agrária, das condições de trabalho, da relação com a natureza, do número de intermediários, remuneração dos trabalhadores e distância geográfica entre outras.

Ainda, segundo Gonçalves e Mascarenhas (2018, p. 254), em todo o mundo existem experiências de grupos de compra solidária que podem variar suas práticas, mas a essência é a mesma "[...] cidadãos comprometidos a compartilhar riscos e benefícios em diferentes graus e de diferentes formas, mas alinhados na perspectiva comum de contribuir para um novo paradigma nas relações entre campo e cidade”.

Também Betti et al., (2013, p. 290) conceituam o consumidor politizado que "[...] apresenta um ativista individualizado que, inserido em um espectro mais amplo, se conecta a grupos que lhe fornecem identidades e, consequentemente, influenciam suas escolhas como consumidor". Assim, o consumidor que convive com o produtor, mesmo que no momento da compra ou na visita em sua propriedade, cria laços de confiança e também de solidariedade que reforça a estratégia de estreitamento das relações produtor-consumidor, que é preconizada pelas experiências bem sucedidas de produção agroecológica.

Segundo Brandenburg et al. (2013), existem sinais de crescimento da comercialização em circuitos curtos no Brasil. Em 2019, de acordo com registros do Instituto Brasileiro de Defesa do Consumidor (Idec), o País conta com 773 feiras orgânicas ou agroecológicas e 66 grupos de consumo responsável, distribuídos pelos 26 estados brasileiros e no Distrito Federal (IDEC, 2019). E a cada ano surgem novas formas de distribuição de alimentos, como as lojas virtuais, cestas diversificadas, feiras noturnas, vendas e degustação na propriedade, restaurantes e merenda escolar orgânicos, dentre outros (DAROLT, 2013).

Em Curitiba, por exemplo, esse crescimento se verifica a partir de dados oficiais da Prefeitura, que por meio da Portaria 044, de ...., de 2007 regulamentou as feiras ecológicas que são muito populares no município e, atualmente são 20 feiras orgânicas certificadas, cujo principal objetivo, além 
de dar acesso a uma alimentação saudável e cuidado com o meio ambiente, produzida sustentavelmente, aproxima produtores de consumidores (CURITIBA, 2019).

Outro dado concreto de crescimento dos circuitos curtos de comercialização é apresentado por Perez-Cassarino e Meireles, (2018, p. 273), ao se referir as feiras realizadas por agricultores familiares da Rede Ecovida de Agroecologia, estima-se em 250 feiras ecológicas atualmente, em todos os Núcleos Regionais que integram a rede nos três estados do Sul do Brasil; as feiras são vistas pela rede "[...] como a expressão mais genuína do que ela busca como estratégia de comercialização. São um instrumento fundamental para popularizar e democratizar o acesso a produtos ecológicos".

Nesse cenário de diversificação de canais de comercialização, Darolt et al. (2015) apontam que a maioria dos produtores tem utilizado simultaneamente mais de um canal de venda, dentre: feiras do produtor, entrega de cestas em domicílio e, mais recentemente, compras governamentais (Programa de Aquisição de Alimentos e o Programa de Alimentação Escolar). Segundo Darolt (2013), os circuitos curtos de comercialização representam para o consumidor afastar-se da:

[...] padronização imposta pelo sistema agroalimentar industrial que uniformiza modos de vida e direciona o consumo. [...] O consumidor consciente busca nos mercados locais produtos com a cara do produtor, nos quais sejam ressaltadas as características locais das comunidades, como as tradições, o modo de vida, a valorização do saber-fazer, o cuidado com a paisagem, além de produtos ecológicos, de época e com preços justos. (DAROLT, 2013, p. 166).

Destarte, a síntese dessas relações pode ser observada nas palavras de Brandão (2007, p. 55) “[...] nem tudo que se produz é consumo, nem tudo que se troca é mercadoria [...] as pessoas consomem comida e símbolos e trocam bens e sentimentos de vida”.

\section{A Experiência de uma Rede de Comercialização no Litoral do Paraná}

O litoral do Estado do Paraná ocupa uma área de $6.058 \mathrm{~km}^{2}$ do bioma Mata Atlântica, fazendo divisa com o litoral de São Paulo, ao norte, e de Santa Catarina, ao sul. Localmente é representada por diversas fisionomias vegetais, em grande parte florestal e caracterizada pelas formas de relevo da Serra do Mar e da Planície Litorânea (TIEPOLO, 2015). Possui cerca de 265 mil habitantes, divididos em sete municípios, sendo: Antonina, Guaraqueçaba, Guaratuba, Matinhos, Morretes, Paranaguá e Pontal do Paraná. 
Em relação à economia, existem particularidades de acordo com cada município. Como reitera Pierri et al. (2006), as características econômicas podem ser simplificadas pelas principais formas de uso do solo costeiro, ou seja, portuário, agrícola, pesqueiro, turístico e os destinados à conservação dos ecossistemas e sua diversidade biológica. Cabe ressaltar que as paisagens litorâneas do estado do Paraná representam os últimos remanescentes contínuos de Mata Atlântica do Brasil, relativamente bem conservados graças às características geomorfológicas regionais, aos processos históricos de ocupação do litoral e a presença de Unidades de Conservação, com destacada riqueza natural, sendo intitulada como Reserva da Biosfera pela UNESCO (TIEPOLO, 2015; PIERRI et al., 2006). Porém, a região se caracteriza pelo paradoxo entre riqueza natural e pobreza social (ESTADES, 2003).

Nesse contexto formado por diferentes aspectos econômicos e sociais, além de se caracterizar como um mosaico cultural, surge a Motirõ Sociedade Cooperativa. A Motirõ foi uma organização sem fins lucrativos fundada no ano de 2009 , que teve por objetivo o planejamento e organização do ambiente urbano e rural, de modo a otimizar a interação ser humano-ambiente, desenvolvendo atividades de elaboração, execução e monitoramento de ações e projetos, atuando sobre questões que concernem a fatores sócio-econômico-ambientais (MATINHOS, 2010, p. 1).

Assim, no ano de 2011, a Motirõ Sociedade Cooperativa - formada por alunos, ex-alunos, professores da Universidade Federal do Paraná/ Setor Litoral e colaboradores de diversas áreas do conhecimento - deu início ao Projeto intitulado "Redes de Comercialização", que teve como principal objetivo fomentar o desenvolvimento territorial local a partir de outras formas de comercializar alimentos. Segundo Brandenburg et al. (2013, p. 9), esses canais, independente da denominação, conferem “[...] uma proximidade entre produtores e consumidores, [...] reforçam a noção de autonomia e conferem um maior peso e participação de consumidores e produtores na definição dos modos de produção, troca e consumo".

Paraadentrarmos na experiência do Projeto "Redes de Comercialização", é preciso ultrapassar o senso comum que resume o mercado apenas nas relações competitivas de oferta e demanda e nos sistemas de preço, para assumir que os mercados podem ser interpretados como um fato social (SCHNEIDER, 2016). Nesse sentido, pode-se dizer que:

[...] os mercados fazem parte dos processos sociais de produção e reprodução das atividades econômicas das unidades familiares, influenciam a vida das pessoas, os seus valores e sua cultura, moldam e modificam instituições e são motivos para conflitos, protestos e disputas. [...] é toda a manifestação de caráter coletivo e coercitivo que influencia as atitudes, os valores e a ação dos indivíduos. (SCHNEIDER, 2016, p. 95). 
Segundo Schneider (2016), não é possível compreender os mercados sem explicar sua origem, quem são os agentes participantes de sua formação e funcionamento, e como se constituem as assimetrias entre os participantes desses mercados. Buscando ir além do senso comum, o autor traz três formas de definição para situar as discussões sobre mercados, que são:

a) o mercado como um locus, um espaço físico determinado em que se realizam trocas materiais de produtos e mercadorias;

b) o mercado como princípio ordenador da sociedade e da economia, tal como funciona o capitalismo; e

c) o mercado como uma construção social, que resulta de processos de interação entre agentes que trocam e intercambiam por diferentes motivos, sejam eles econômicos, sociais ou culturais.(SCHNEIDER, 2016, p. 97).

Dadas as definições, a Motirõ Sociedade Cooperativa atuou tendo como base o mercado como uma construção social. Tratando-se dos tipos de mercados existentes na agricultura familiar, Schneider (2016), apresenta quatro tipos de mercados em que os agricultores familiares se inserem, a saber: 1) Mercados de proximidade; 2) Mercados locais e territoriais; 3) Mercados convencionais; e 4) Mercados públicos e institucionais. O Projeto Redes de Comercialização enquadra-se no tipo 2 - Mercados locais e territoriais, nos quais:

[...] as trocas passam a ser monetizadas e se configura uma situação de intercâmbio cada vez mais orientada pela oferta e demanda, assim como critérios e indicadores quantitativos [...]. A distinção principal em relação aos mercados de proximidade está no fato de que a distribuição e a circulação dos produtos e mercadorias deixam de ser feita diretamente por quem produz e passa a existir um intermediário, que possui interesses e custos [...]. Estes mercados mantêm um locus ligado a determinados espaços, mas o seu local de atuação e os canais de comercialização já não ficam confinados a este local. À medida que cresce a demanda por produtos agroalimentares diferenciados e as possibilidades logísticas se tornam acessíveis, o território de atuação desses mercados se expande para fora de um lugar determinado. Em alguns casos, podem surgir nichos específicos. Um aspecto interessante do processo de des(re)territorialização desses mercados é o fato de que os produtos e mercadorias que transitam nestes circuitos carregam consigo as "marcas" de origem que enfatizam e valorizam tanto a procedência material dos produtos (às vezes até por meio de dispositivos formais como as indicações geográficas) como sua identidade imaterial ou simbólica (por meio de indicações de procedência). As feiras locais e os espaços públicos de venda, como leilões e outros, são exemplos eloquentes desses mercados. (SCHNEIDER, 2016, p. 123-124).

A partir desse contexto, apresenta-se o projeto "Redes de Comercialização", que foi subdividido em cinco fases que serão apresentadas 
a seguir em forma de relato de experiência, tendo como base referencial o trabalho intitulado "Plano de Negócios Redes de Comercialização" de Mendonça e Aguida (2016), além da experiência de uma das autoras do presente artigo como membra da Motirõ Sociedade Cooperativa.

\section{i) Fase 1 - Surgimento da ideia}

A partir do contato com agricultores familiares do litoral paranaense, resultando no projeto de extensão: "Feiras: construir caminhos de inclusão social via processos de gestão de mercados com as comunidades de agricultores familiares do litoral paranaense" (2007-2009), desenvolvido pela Universidade Federal do Paraná/Setor Litoral, sob a coordenação do professor Manoel Flores Lesama. Esse projeto resultou na formação da "Matinfeira", feira realizada no município litorâneo de Matinhos com o intuito de proporcionar um canal de venda para escoar produtos advindos da agricultura familiar da região.

As principais características da Fase 1 são: a) a comercialização mensal dos produtos; b) os pedidos realizados por meio de uma lista de e-mail enviada aos consumidores, com os produtos disponibilizados pelos produtores; c) a entrega dos produtos realizada por meio de uma partilha agroecológica, na qual os consumidores retiravam seus produtos em determinado dia e horário nas dependências da UFPR/Setor Litoral e, d) o caráter da chamada partilha agroecológica era de confraternização e discussão sobre consumo consciente. Nesse primeiro momento, o foco principal do Projeto Redes de Comercialização não era a venda em si, e sim a aproximação entre consumidores e produtores, proporcionando a disseminação de produtos de origem agroecológica.

\section{ii) Fase 2 - Compras Coletivas de Produtos Agroecológicos no Litoral do} Paraná

No ano de 2012, o Projeto Redes de Comercialização foi registrado como um projeto de extensão dentro da universidade, por meio do Programa de Benefícios Econômicos para Manutenção aos Estudantes de Graduação e Ensino Profissionalizante (PROBEM) da UFPR.

A principal característica da Fase 2, para além das características já apresentadas na Fase 1 do Projeto, foi o aumento da equipe com a entrada de bolsistas por intermédio do projeto de extensão, e a disponibilização de veículos da universidade para fins de logística.

iii) Fase 3 - Projeto Redes de Comercialização e a Secretaria da Ciência, Tecnologia e Ensino Superior do Paraná (SETI)

Ainda no ano de 2012, a cooperativa Motirõ obteve da Secretaria da Ciência, Tecnologia e Ensino Superior do Governo do Estado do Paraná 
(SETI) patrocínio para o desenvolvimento das atividades do "Redes de Comercialização". O edital da SETI foi elaborado especificamente para a região do litoral devido aos desastres ambientais decorrentes de fortes chuvas que assolaram a região em 2011. Esse projeto foi executado no período de 2013 a 2014.

Entre as principais características da Fase 3, tem-se: a) prestação de contas das atividades propostas no projeto; $b$ ) desenvolvimento de temáticas de acesso a mercados, comercialização, certificação de alguns agricultores da região e também contribuição para a formação e organização de grupos de agricultores e consumidores no litoral do Paraná; e, c) criação de um grupo de consumo em Pontal do Paraná.

\section{iv) Fase 4 - Criação do Site}

Com o fim do financiamento do projeto pela SETI, em 2014, o objetivo da equipe era tornar o Projeto Redes de Comercialização autossustentável, e nessa busca surgiu a proposta de um site de vendas dos produtos. A criação do site proporcionou grande mudança na forma de atuação do projeto, principalmente em relação à postura da equipe, pois o espaço virtual se mostrou eficiente, porém não o suficiente para manter o projeto de forma autossustentável.

As principais características da Fase 4 compreendem: a) desenvolvimento do site; b) estruturação de dois Planos de Marketing; c) mudança de posicionamento da equipe; d) investimento em publicidade.

\section{v) Fase 5 - Cestas in Natura}

Com os resultados obtidos por meio do site, a equipe do Projeto Redes de Comercialização juntamente dos produtores atuantes no projeto, decidiram atuar também na Feira Livre de Matinhos (Matinfeira). Esse acesso a um novo mercado foi extremamente importante para o andamento do projeto, pois além de permitir a entrada de novos produtores, alavancou as buscas por produtos in natura na venda pelo site, e viabilizou a entrega de cestas a domicílio nos municípios de Matinhos e Pontal do Paraná.

O Projeto Redes de Comercialização teve atuação até meados de 2017, momento pelo qual o País passou pela violação dos princípios do processo democrático e da ordem constitucional brasileira, com o subsequente desmantelamento dos direitos sociais e das políticas públicas, acarretando no desligamento das ações da Motirõ Sociedade Cooperativa até o presente momento.

Como visto no contexto da Motirõ, mas que também pode se aplicar a outros contextos, o aporte governamental, seja por intermédio de financiamento de projetos ou implementação de políticas públicas, 
é essencial na consolidação de outros estilos de desenvolvimento e no fortalecimento dos sistemas agroalimentares locais. Para Azevedo (2016, p. 225), “[...] no caso específico da agricultura familiar, cooperativas, associações e o poder público são os principais mecanismos de ação coletiva para a criação dos mercados”. Para isso, são necessários:

[...] esforços coordenados e intencionais, que fazem a ponte entre a ação dos indivíduos e a construção das instituições de mercados. [...] Daí a importância da ação coletiva para fazer emergir padrões de qualidade, canais de comercialização e fluxo de informação que permitam constituir um mercado multilateral. (AZEVEDO, 2016, p. 221).

Tendo em vista a dificuldade de acesso dos agricultores familiares aos mercados hegemônicos, faz-se necessária a criação e construção de novos mercados, por meio da implantação de outros tipos de canais de comercialização. Desse modo, pode-se afirmar que a experiência do Projeto Redes de Comercialização da Motirõ Sociedade Cooperativa para a consolidação de um novo modelo de desenvolvimento rural, evidenciou outras formas de comercialização de alimentos e produtos locais, aproximando produtores e consumidores, bem como aportou maior autonomia aos produtores. Para Veiga (2006, p. 166), “[...] os mercados são tão somente uma entre as várias instituições que participam do processo de desenvolvimento.", porém a construção de mercados mais justos pode significar um passo importante para atingir um desenvolvimento que seja social, econômico e ambientalmente sustentável.

\section{Considerações Finais}

Como conciliar a proteção ao meio ambiente, o respeito à natureza, à restauração da biodiversidade, a valorização da diversidade cultural, o respeito às tradições e o desenvolvimento do território? Trata-se aqui de nos questionarmos sobre uma dupla exigência - estabelecida especialmente pelos fóruns internacionais - de proteção da natureza como uma condição indispensável para a sobrevivência do planeta e do encorajamento à expressão da diversidade cultural como suporte ao desenvolvimento. Diante da complexidade das interações entre a diversidade cultural, o ambiente e as dinâmicas de desenvolvimento, o mundo rural nos aporta ricas experiências. As políticas de gestão da natureza, as políticas culturais e as políticas de desenvolvimento econômico, na maioria das vezes, estão sendo propostas e implementadas de forma dissociadas, como se houvesse o Homem de um lado e a Natureza do outro.

As questões ambientais e de desenvolvimento, tanto em esfera global como local, encontram-se atreladas aos sistemas agroalimentares. É preciso 
trilhar novos caminhos na busca pela sustentabilidade da produção de alimentos e da reprodução social dos camponeses, com vista à soberania e segurança alimentar, ressignificando as relações sociais campo-cidade, ou seja, onde se dá a produção do alimento e encontram-se seus consumidores.

A exemplificação de um movimento atuante numa nova forma de se comercializar alimentos, mostra-nos que outros caminhos além da estrutura social hegemônica que nos é imposta são possíveis, mas para que essas novas propostas de desenvolvimento de fato aconteçam, faz-se necessário um novo olhar acerca do que é desenvolver-se como sociedade, buscando o equilíbrio entre ser humano e natureza, fazendo emergir uma nova realidade socioeconômica alinhada às questões ambientais.

\section{Agradecimentos}

O presente trabalho foi realizado com apoio da Coordenação de Aperfeiçoamento de Pessoal de Nível Superior - Brasil (CAPES) - Código de Financiamento 001.

\section{Referências}

AZEVEDO, P. F. Emergência de instituições de mercado: a criação de mercados como política para a agricultura. In: MARQUES, F. C.; CONTERATO, M. A.; SCHNEIDER, S. (org.). Construção de mercados e agricultura familiar: desafios para o desenvolvimento rural. Porto Alegre: UFRGS, 2016. p. 209-227.

ALBUQUERQUE, A. C. C. O socialismo na perspectiva da sociedade civil Latino-americana: algumas considerações. In: FERREIRA, L. C. (org.). A questão ambiental na América Latina: teoria social e interdisciplinaridade. Campinas: Unicamp, 2011. p. 237-255.

BETTI, P. et al. O consumo politizado como resposta à crise socioambiental: as justificativas sociais da compra de produtos orgânicos em feiras-livres de Curitiba. In: NIEDERLE, P. A.; ALMEIDA, L.; VEZZANI, F. M. (org.). Agroecologia: práticas, mercados e políticas para uma nova agricultura. Curitiba: Kairós, 2013. p. 267-294.

BRANDÃO, C. R. Tempos e espaços nos mundos rurais do Brasil. Ruris, Campinas, v. 1, n. 1, p. 37-64, mar. 2007.

BRANDENBURG, A.; DAROLT, M. R.; LAMINE, C. A diversidade dos circuitos curtos de alimentos ecológicos: ensinamentos do caso brasileiro e francês. Agriculturas - Experiências em Agroecologia, Rio de Janeiro, v. 10, n. 2, p. 8-13, jun. 2013.

CURITIBA. Portaria 044/2007, Regulamenta as atividades das Feiras Orgânicas em Curitiba. 2007. Disponível em: https://mid.curitiba.pr.gov.br/2019/00272118. pdf. Acesso em: 2 nov. 2019.

DAROLT, M. R. Circuitos curtos de comercialização de alimentos ecológicos: reconectando produtores e consumidores. In: NIEDERLE, P. A.; ALMEIDA, L.; 
VEZZANI, F. M. (org.). Agroecologia: práticas, mercados e políticas para uma nova agricultura. Curitiba: Kairós Edições, p. 139-170, 2013.

DAROLT, M. R. et al. Redes alimentares alternativas e novas relações produçãoconsumo na França e no Brasil. In: BRANDENBURG, A.; BILLAUD, J. P.; LAMINE, C. (org.). Redes de Agroecologias: experiências no Brasil e na França. Curitiba: Kairós Edições, 2015. p. 111-133.

ESCOBAR, A. La invención del tercer mundo. Construcción y deconstrucción del desarrollo. Venezuela: Fundación Editorial el perro y la rana, 2007.

ESTADES, N. P. O Litoral do Paraná: entre a riqueza natural e a pobreza social. Desenvolvimento e Meio ambiente, Curitiba, v. 8, p. 25-41, jul./dez. 2003. Disponível em: https://revistas.ufpr.br/made/article/view/22047/14408. Acesso em: 2 nov. 2019.

FERREIRA, L. C. et al. Questão ambiental na América Latina: teoria social e interdisciplinaridade. In: FERREIRA, L. C. (org.). A questão ambiental na América Latina: teoria social e interdisciplinaridade. Campinas: Unicamp, 2011. p. 19-43.

FRIEDMANN, H.Uma economia mundial de alimentos sustentável. In: MALUF, R; FRIEDMANN, H.; BELIK, W. Abastecimento e segurança alimentar: os limites da liberalização. Campinas: IE/Unicamp, 2000.

FURTADO, C. O mito do desenvolvimento econômico. Rio de Janeiro: Paz e Terra, 1974.

FURTADO, C. Os desafios da nova geração. Revista de Economia Política, São Paulo, v. 24, n. 4, p. 483-486, out./dez. 2004.

FURTADO, C. Pequena introdução ao desenvolvimento: enfoque interdisciplinar. São Paulo: Nacional, 1980.

GLIESSMAN, S. R. Agroecologia: processos ecológicos em agricultura sustentável. Porto Alegre: UFRGS, 2000.

GONÇALVES, J.; MASCARENHAS, T. Grupos de consumo responsável no Brasil: aproximando consumidores e produtores em redes agroecológicas e solidárias. In: PEREZ-CASSARINO, J. et al. (org.). Abastecimento alimentar: Redes alternativas e mercados institucionais. Chapecó: UFFS; Praia Cabo Vede: UNICV, 2018. 251-266.

GUDYNAS, E. Desarrollo, extractivismo y buen vivir. Debates sobre el desarrollo y sus alternativas en América Latina: Una breve guía heterodoxa. In: LANG, M.; MOKRANI, D. (comp.). Más allá del desarrollo. Quito: Fundación Rosa Luxemburgo/Abya Yala, 2011. p. 21-53.

GUIMARÃES, R.P.; BEZERRA, J.Novas questões ou velhos problemas: a posição do Brasil na agenda internacional do meio ambiente. In: FERREIRA, L. C. (org.). A questão ambiental na América Latina: teoria social e interdisciplinaridade. Campinas: Unicamp, 2011. p. 83-97.

HACON, V. S.; LOUREIRO, C. F. Estruturas de poder e a questão ambiental: a reprodução da desigualdade de classe. Desenvolvimento e Meio ambiente, Curitiba, v. 29, p. 59-69, abr. 2014. 
INSTITUTO BRASILEIRO DE DEFESA DO CONSUMIDOR (IDEC). Mapa de Feiras Orgânicas, 2019. Disponível em: https://feirasorganicas.org.br/. Acesso em: 24 ago. 2019.

MATINHOS. Registro sob n. 41400020771, de 25 de novembro de 2010. Dispõe sobre o Estatuto da Motirõ Sociedade Cooperativa. Matinhos, 2010. 8 p.

MAX-NEEF, M. Desenvolvimento à escala humana: concepção, aplicação e reflexões posteriores. Tradução: Rede Viva. Blumenau: Edifurb, 2012.

MENDONÇA, C. S.; AGUIDA, L. F. Plano de Negócios Redes de Comercialização. 2016. Trabalho de Conclusão de Curso (Bacharelado em Gestão e Empreendedorismo) - Programa de Pós-Graduação em Gestão e Empreendedorismo. Universidade Federal do Paraná, Setor Litoral, Matinhos, 2016.

PEREZ-CASSARINO, J. Agroecologia, mercados e sistemas agroalimentares: uma leitura a partir da soberania e segurança alimentar e nutricional. In: COSTA GOMES, J. C.; ASSIS, W. S. Agroecologia: princípios e reflexões conceituais. Brasília, DF: Embrapa, 2013.

PEREZ-CASSARINO,J.; FERREIRA, A. D. D. Agroecologia, construção social de mercados e a constituição de sistemas agroalimentares alternativos: uma leitura a partir da Rede Ecovida de Agroecologia. In: NIEDERLE, P. A.; ALMEIDA, L.; VEZZANI, F. M. (Org.) Agroecologia: práticas, mercados e políticas para uma nova agricultura. Curitiba: Kairós Edições, 2013.

PEREZ-CASSARINO,J.;MEIRELES,L.Rede Ecovida de Agroecologia:origens, princípios e sua concepção de comercialização. In: PEREZ-CASSARINO, J. et al. (org.). Abastecimento alimentar: redes alternativas e mercados institucionais. Chapecó: UFFS; Praia Cabo Verde: UNICV, 2018. p. 267-295.

PIERRI, N. et al. A ocupação e o uso do solo no litoral paranaense: condicionantes, conflitos e tendências. Desenvolvimento e Meio ambiente, Curitiba, n. 13, p. 137-167, 2006.

PLOEG, J. D. V. der. Camponeses e Impérios Alimentares: lutas por autonomia e sustentabilidade na era da globalização. Porto Alegre: UFRGS, 2008.

PROGRAMA DAS NAÇÕES UNIDAS PARA O MEIO AMBIENTE (PNUMA). Manifiesto por la vida: por una ética para la sustentabilidad, Ambiente \& Sociedade, [s.l.], Ano V, n. 10, $1^{\circ}$ sem. 2002.

SACHS, I. Barricadas de ontem, campos de futuro. Estudos Avançados, São Paulo, v. 24, n. 68, p. 25-38, 2010.

SCHNEIDER, S. Mercados e agricultura familiar. In: MARQUES, F. C.; CONTERATO, M. A.; SCHNEIDER, S. (org.). Construção de mercados e agricultura familiar: desafios para o desenvolvimento rural. Porto Alegre: UFRGS, 2016. p. 93-140.

TIEPOLO, L. M. A inquietude da Mata Atlântica: reflexões sobre a política do abandono em uma terra cobiçada. Revista Guajú, Matinhos, v. 1, p. 96-109, jul./ dez. 2015.

TOMMASINO, H.; FOLADORI, G.; TAKS, J. La crisis ambiental contemporánea. In: FOLADORI, G.; PIERRI, N. (org.). Sustentabilidad? 
Desacuerdos sobre el desarrollo sustentable. México: Universidad Autónoma de Zacatecas, 2005. p. 9-26.

VEIGA, J. E. Meio ambiente \& desenvolvimento. 3. ed. São Paulo: Senac, 2006.

VIEIRA, P. F. Políticas ambientais no Brasil: do preservacionismo ao desenvolvimento territorial sustentável. Política \& Sociedade, São Paulo, v. 8, n. 14, p. 27-75, 2009.

ZANONI, M.; RAYNAUT, C. Meio ambiente e desenvolvimento: imperativos para a pesquisa e a formação. Reflexões em torno do doutorado da UFPR. Desenvolvimento e Meio ambiente, Curitiba, v. 33, p. 9-30, abr. 2015. (Originalmente publicado em Cadernos em Desenvolvimento e Meio Ambiente, v. 1. 1994).

ZAOUAL, H. Globalização e diversidade cultural. São Paulo: Cortez, 2003.

Recebido em: 30/08/2019

Aceito em: 30/10/2019 


\title{
AGRIFOOD SYSTEMS AND MARKETING NETWORKS: ANOTHER ENVIRONMENT-SOCIETY RELATIONSHIP
}

\begin{abstract}
Environmental issues permeate all sectors of contemporary society, whether in the economic, political and social spheres. The environmental crisis presents itself as the manifestation of the hegemonic civilizatory patterns of relating to the environment, ideologically focused on progress and growth. In order to face such problems, it is necessary to rethink the relationship between society and nature from a profound transformation of man's perspective towards the environment and as part of it. Moreover, it can't be admitted that only one way of life, production and reproduction prevails over others. In this sense, the present work seeks to identify how socio-environmental and development issues permeate agrifood systems, as well as forms of resistance and re-signification of the social relations focused on the commercialization of food, presenting the experience of the Project Redes de Comercialização from Cooperativa Motirõ in the Coast of Paraná, as promoter of another logic of food commercialization. Tracing new paths in the quest for the sustainability of food production and social reproduction of peasants, with a view to food sovereignty and security, re-signifying the rural-city social relations, that is, where the food is produced and its consumers are found.
\end{abstract}

Keywords: Nature-Society. Local development. Short circuits of commercialization.

\section{SISTEMAS AGROALIMENTARIOS Y REDES DE COMERCIALIZACIÓN: OTRA RELACIÓN AMBIENTE-SOCIEDAD}

\begin{abstract}
Resumen
Los problemas ambientales impregnan todos los sectores de la sociedad contemporánea, ya sea en el ámbito económico, político y social. La crisis ambiental se presenta como la manifestación de los patrones de civilización hegemónicos relacionados con el medio ambiente, ideológicamente orientados hacia el progreso y el crecimiento. Para enfrentar tales problemas, es necesario repensar la relación Sociedad-Naturaleza desde una profunda transformación de la perspectiva del hombre ante el medio ambiente y como parte de este. Además, no puede aceptarse que solo una forma de vida, producción y reproducción prevalezca sobre las demás. En este sentido, el presente trabajo busca identificar cómo los problemas socioambientales y de desarrollo impregnan los sistemas agroalimentarios, así como las formas de resistencia y resignificación de las relaciones sociales centradas en la comercialización de alimentos, presentando la experiencia del Proyecto "Comercialización en red" de la Cooperativa Motirõ, en la costa del estado de Paraná, como promotor de otra lógica de comercialización de alimentos. Recorriendo nuevos caminos en la búsqueda de la sostenibilidad de la producción de alimentos y la reproducción social de los campesinos, con miras a la soberanía y seguridad alimentaria, resignificando las relaciones sociales campo-ciudad, es decir, donde se producen los alimentos y se encuentran sus consumidores.
\end{abstract}

Palabras clave: Naturaleza-Sociedad. Desarrollo local. Circuitos locales. 